\title{
The early stages of thrombosis
}

\author{
J. C. F. POOLE, J. E. FRENCH, AND W. J. CLIFF
}

From the Sir William Dunn School of Pathology, Oxford

A thrombus, which was defined by Welch (1899) as 'a solid mass or plug formed in the living heart or vessels from constituents of the blood', is to be distinguished on morphological grounds from a clot, which is the material formed when blood is allowed to solidify under static conditions outside the body. This point has been considered in detail elsewhere (Poole, 1959, 1960a, b; Poole and French, 1961; French, 1962; Poole, 1963) and will not be further elaborated here. The main difference is that in a clot the platelets are distributed at random and are not agglutinated, whereas a thrombus contains extensive regions which consist of masses of agglutinated platelets. This statement must be qualified by saying that if shed blood is agitated instead of being allowed to solidify under static conditions, platelet agglutination takes place to a variable degree depending on the nature and extent of the agitation. Certain types of agitation can lead to the formation in vitro of objects which bear a striking morphological resemblance to naturally occurring or experimentally induced thrombi. The examination of such objects, which are usually called artificial thrombi, has in the last few years been of assistance in enlarging our knowledge of the natural process, as will be explained below.

The fundamental facts about the sequence of events leading to the formation of a thrombus were established in the nineteenth century largely by observations on the effects of injury on living vessels examined microscopically. In the course of these studies it was found that the initial stages in the formation of a haemostatic plug were very similar: in both cases it was seen that platelets were deposited first at the site of injury, followed by leucocytes, followed after a variable period of time by fibrin with trapped red cells and a few scattered leucocytes. The principal investigations which led to the establishment of these facts are listed in Table I.

Wharton Jones (1852) seems to have been the first to observe the early stages of thrombosis in a mammalian vessel. He saw that 'granular lymphy material' was deposited at the site of injury. His description and illustration leave little doubt that he was seeing platelets being deposited but he did not apparently connect his observations with those of

\begin{tabular}{lll} 
& \multicolumn{2}{l}{ T A B L I } \\
Author & Year & Preparation Examined \\
\hline Wharton Jones & 1851 & Web of frog's foot \\
Wharton Jones & 1852 & Wing of bat \\
Mantegazza & 1869 & Mesentery of frog \\
Zahn & 1875 & Mesentery of frog \\
Bizzozero & 1882 & Mesentery of guinea-pig and \\
& & rabbit \\
Hayem & 1882 & Jugular vein of dog \\
Lubnitzky & 1885 & Limb artery of rabbit \\
Eberth and Schimmelbusch & 1886 & Various mammalian vessels \\
Welch & 1887 & Mesentery of dog
\end{tabular}

Donné (1842) and Zimmermann (1845) who had already published the earliest descriptions of platelets. The other three studies published before 1882 were on frog vessels and the mistake was made of supposing that the first event in thrombosis was the deposition of leucocytes, an understandable mistake, since the 'platelets' of amphibia have nuclei. It was left to Bizzozero (1882) to demonstrate clearly that thrombosis began with the deposition of platelets at the site of injury. In the same year Hayem showed that the same was true of the earliest stages in the formation of a haemostatic plug. Hayem's observations were confirmed and extended by Lubnitzky (1885) who examined histological sections of developing haemostatic plugs, found that areas obviously consisting of platelets merged imperceptibly with areas of apparently structureless material, and concluded (wrongly, as we now know) that the platelets gradually fused into a homogeneous mass in which the outlines of individual platelets were lost. The most extensive of the nineteenth century studies was that of Eberth and Schimmelbusch (1886) who repeated the work of their predecessors using a variety of different mammalian vessels. The essential findings were confirmed yet again by Welch (1887). This series of studies was so thorough and complete that until comparatively recently little further progress was possible. In the past few years our knowledge of the early stages of thrombosis has been enlarged by the use of the electron microscope to study naturally occurring and experimentally induced thrombi; by the study of artificial thrombi; and by electron microscopy of artificial thrombi.

The electron microscopical studies which have so 
far been published on the structure of naturally occurring, experimentally induced and artificial thrombi, and of haemostatic plugs, are summarized in Table II. The list does not include studies on the morphology of aggregates of isolated platelets or those which are concerned with the formation of platelets; such studies are both valuable and relevant but their exact connexion with thrombosis awaits further elucidation.

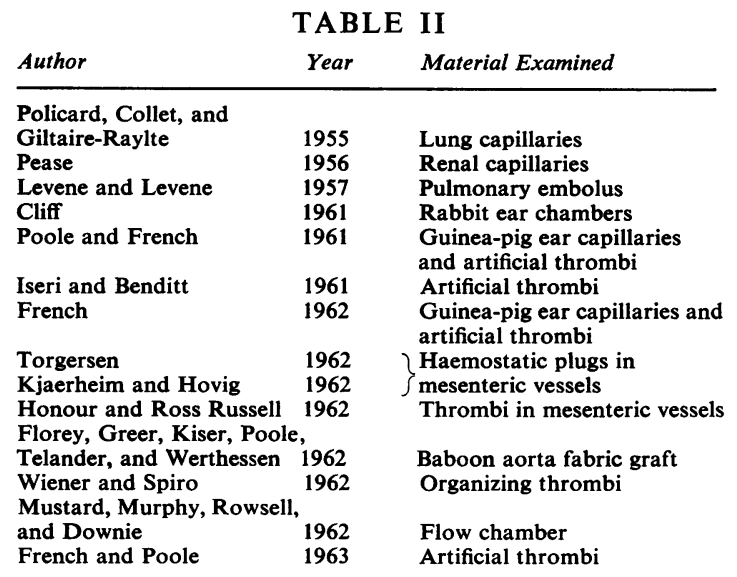

\section{ELECTRON MICROSCOPY OF \\ NATURALLY OCCURRING AND EXPERIMENTALLY INDUCED THROMBI}

The studies of Policard, Collet, and GiltaireRaylte (1955) and of Pease (1956) did little more than re-state the fact that the first event in thrombosis is the deposition of platelets. Pease pointed out that the platelets might be arranged in a loosely or a closely packed way. Levene and Levene (1957) established that in a fully developed human thrombus the platelets were closely packed, not fused, retaining their individual outlines even when their interior structure had largely decomposed. These facts have been confirmed and elaborated in later studies. Figure 1 shows the appearance in the electron microscope of a platelet seen in section in the circulating blood in a small vessel and indicates that the shape of the platelet as seen in living preparations is not obviously altered by the processes of fixation and imbedding for electron microscopy. Figure 2 shows a section through a very early thrombus which was encountered by chance in a small vessel in a rabbit ear chamber. It will be seen that the platelets (P) are only loosely aggregated and only slightly if at all changed from the shape they have when circulating in the blood stream. The loosely packed arrangement of morphologically normal platelets is also shown in Fig. 3, which shows part of a rather large but still quite early thrombus, which was produced by crushing a mesenteric vessel in a rat. The nature? of the process whereby the platelets later come to be closely packed instead of loosely packed is not a? present understood. An example of an early haes mostatic plug as seen in section in the electron micro® scope is illustrated in Fig. 4, which shows a gap in the्छ endothelium of a small vessel in a rabbit ear chamber through which a red blood corpuscle and a granu: locyte are escaping; between them the aperture is plugged with platelets.

\section{THE PRODUCTION OF ARTIFICIAL THROMBI}

A number of attempts have been made at variousi times to produce objects having the histologicaf structure of a thrombus outside the body. The earlier work has been reviewed elsewhere (Poole and French. 1961). For a variety of reasons the earlier methods failed to yield as much new information as mighథ have been hoped for. Chandler (1958) showeç that when blood was made to flow continuousle round a closed circular loop of plastic tubing mounted on a rotating turntable, the blood eventuall solidified, but when it was examined histologically it was found to contain areas strikingly similar ire appearance to a natural thrombus. Using a slight modification of this apparatus Poole (1959) wa? able to obtain conditions under which the blook never solidified completely. Instead, a small solid object was formed just behind the advancing edg of the column of blood which floated round inde finitely after reaching a maximum size in a feu minutes. When examined histologically, these smal? solid objects were found to consist of a "white headō composed of platelets and leucocytes and a 'red tailo composed of fibrin, trapped red blood corpuscles? and a few scattered leucocytes, thus reproducing many of the characteristic features of a natura thrombus. ${ }^{1}$ This technique for the production of artificial thrombi has been used for a variety of purposes so far: to study the effects of anticoagulants (Poole, 1960a); the incorporation of bacteria (Poole, 1960b); the effects of fatty acids (Connop and Poole, 1961; Connor, 1962); and the subsen quent fate of the artificial thrombus when returned to the circulation (Hand and Chandler, 1962). The appearance of these artificial thrombi in the electrot

${ }^{1}$ It was believed at the time that the reason why the results obtaine $\Phi$ by this modification were slightly different from those obtained iff Chandler's original apparatus was that a smoother junction between the ends of the tube had been achieved. Following a recent conversation with Dr. Chandler it has become clear that this is most unlikelQ to be the explanation. The difference was in all probability. due to th fact that in Chandler's original method the turntable rotated in \&. near-horizontal plane, while in the modified technique it rotated in $\Phi$ vertical or near-vertical plane. 


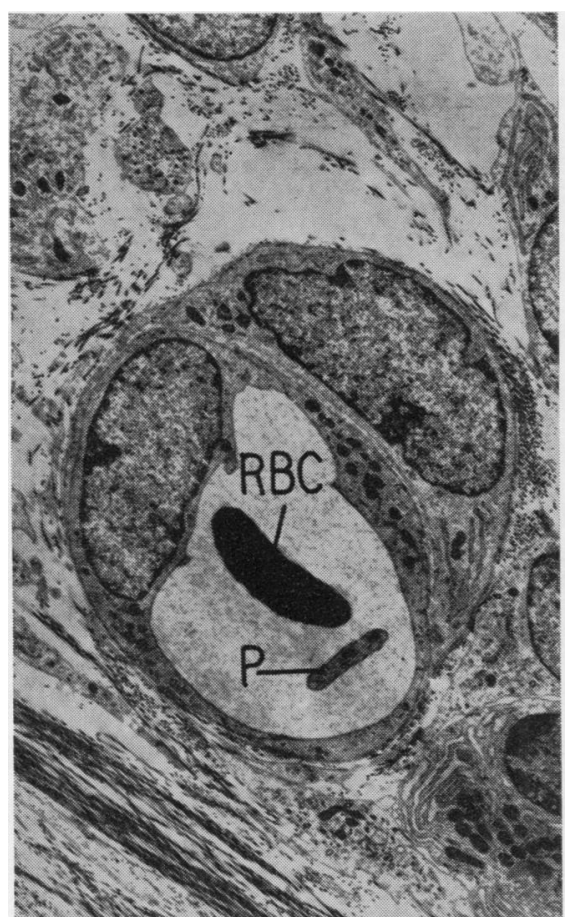

FIG. 1

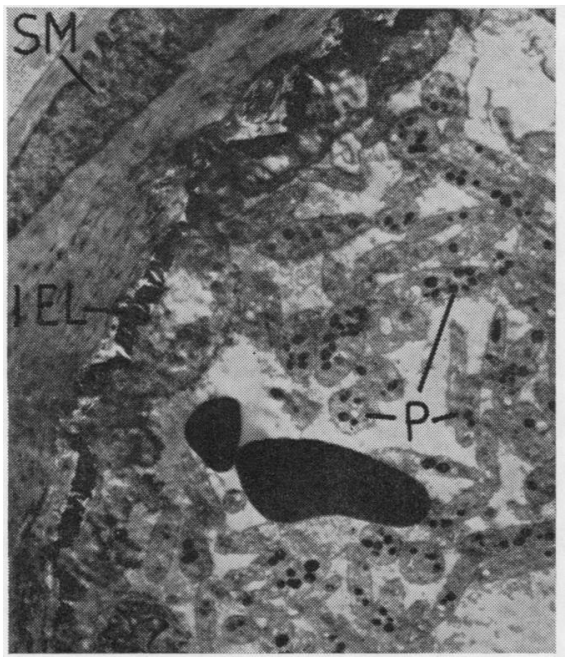

FIG. 3

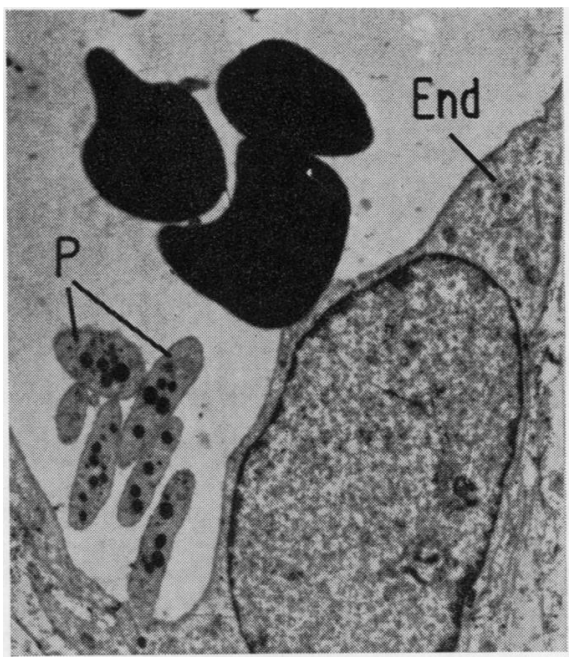

FIG. 2

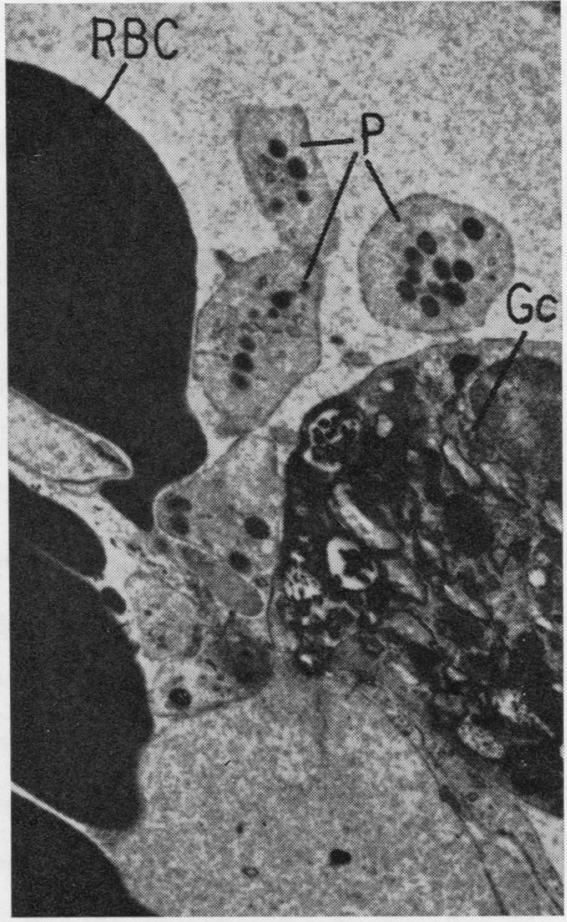

FIG. 4

FIG. 1. Section through a small blood vessel passing through a platelet $(P)$ and a red blood corpuscle $(R B C) . \times 6,000$.

FIG. 2. Section through a very early thrombus showing loosely aggregated platelets $(P)$ attached to the endothelium (End). $\times$ 10,000.

FIG. 3. Section through an early thrombus. Platelets $(P)$ are attached to the amorphous remnants of endothelium overlying the damaged internal elastic lamina (IEL). The cell in the upper left part of the field is a smooth muscle cell $(S M) . \times 6,000$.

FIG. 4. Section through a small haemostatic plug. A red blood corpuscle $(R B C)$ and a granulocyte $(G c)$ are escaping through $a$ hole in the endothelium. The space between is plugged with platelets (P). $\times \quad 15,000$. 


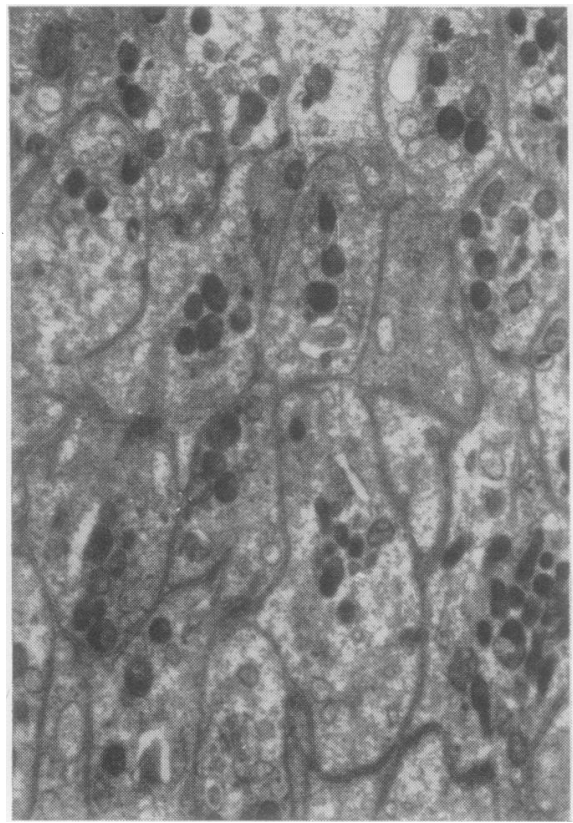

FIG. 5

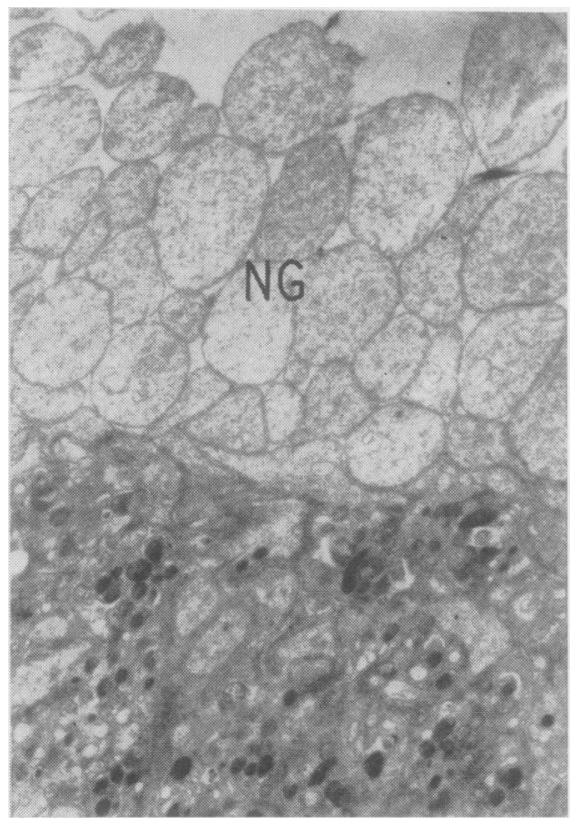

FIG. 7

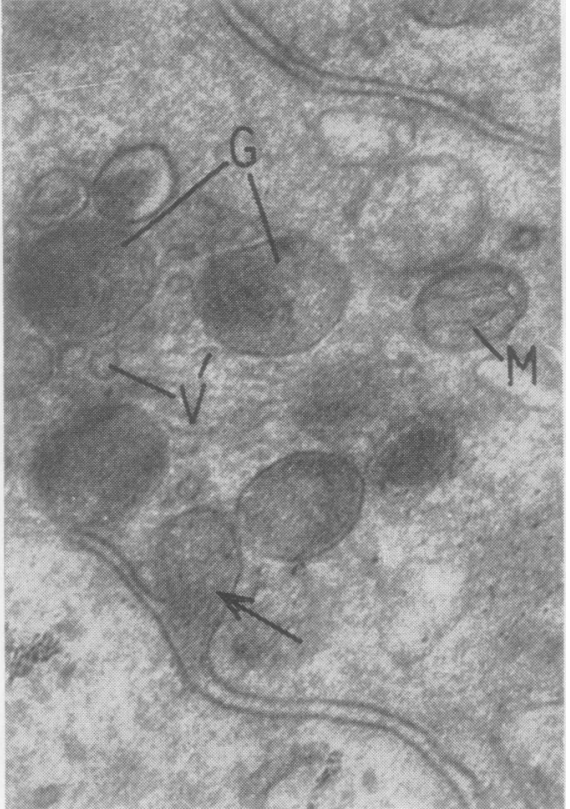

FIG. 6

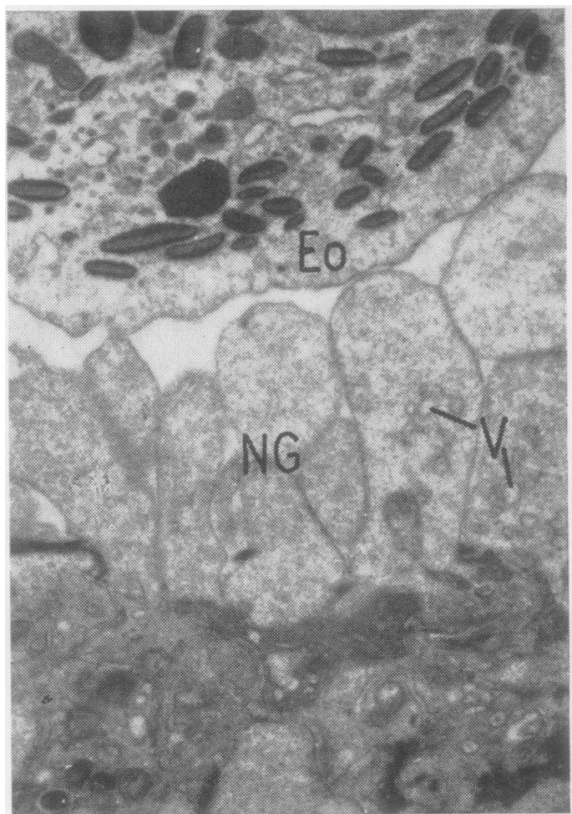

FIG. 8

FIG. 5. Section through the interior of the 'white head' of an artificial thrombus. $\times 16,000$.

FIG. 6. From the same specimen as Figure 5. Granules $(G)$ mitochondria $(M)$, and vesicles $(V)$ are seen. $\times 60,000$.

FIG. 7. Section through the edge of a platelet aggregate in an artificial thrombus, showing non-granular bodies $(N G) . \times 10,000$.

FIG. 8. A field similar to that shown in Figure 7, showing an eosinophil (Eo) attached to the non-granular bodies $(N G)$ which retain their vesicles $(V) . \times 12,000$. 
microscope will be described in the following section.

\section{ELECTRON MICROSCOPY OF ARTIFICIAL THROMBI}

At the present time, for technical reasons, work on the electron microscopy of artificial thrombi is in many respects more advanced than is work on the electron microscopy of natural thrombi. The artificial thrombi are formed more rapidly than are natural thrombi and so well-preserved material is easily obtained. Moreover, there are serious difficulties in locating the lesion where small experimental thrombi are produced in living vessels. It is not at present certain that all the findings to be described in this section are relevant to the natural process; they do, however, provide a useful indication as to what to look for in future studies on the electron microscopy of thrombosis and haemostasis.

Figure 5 shows a section through the interior region of the 'white head' of an artificial thrombus. Closely packed platelets are seen. Though very closely packed and probably having complicated intertwining processes, their boundary membranes are apparently intact. Figure 6 shows part of a similar region at a higher magnification. Three kinds of organelle can be recognized. There are some relatively large, densely osmiophilic granules $(G)$, some small mitochondria $(\mathrm{M})$, and vesicles $(\mathrm{V})$ of variable size and shape. At present very little is known about the nature and properties of platelet organelles and their classification into these three categories is probably an oversimplification. The appearance of the edge of one of these platelet aggregates is shown in Figures 7 and 8. The platelet mass is surrounded by non-granular bodies whose shape, size, and general appearance suggest that they are platelets which have lost their granules and mitochondria but retain some at least of the vesicles. The way in which the granules are lost has not so far been fully ascertained, but fairly frequent examples have been found of the appearance indicated by an arrow in Fig. 6 which suggests that the boundary membrane of a granule fuses with the boundary membrane of the platelet and forms a flask-shaped structure which discharges the contents of the granule into the space between two adjacent platelets. Leucocytes seemed to be attached to the zone of degranulated platelets rather than to platelets which were morphologically intact (Fig. 8).

Similar degranulation of platelets was observed by Parmeggiani (1961) when washed platelets were treated with thrombin. The formation of a zone of degranulated platelets similar to that seen in the artificial thrombi certainly occurs in vivo under certain conditions, but the available information is so far rather scanty. Kjærheim and Hovig (1962) found degranulated platelets in haemostatic plugs. Florey, Greer, Kiser, Poole, Telander, and Werthessen (1962) found similar appearances in the thrombus-like material which initially lines fabric grafts of the aorta. Hoak (1963) found extensive zones of degranulated platelets in the thrombi which are produced by intravenous injection of sodium stearate. He was also able to demonstrate granules with an opening at the surface of the platelet similar to those seen in the artificial thrombi. It may be noted in passing that this mechanism for discharging granules appears to be similar to that described by De Robertis and Vaz Ferreira (1957) in certain cells of the adrenal cortex and to that described by Palade (1959) for the discharge of zymogen granules.

No fibrin could be made out between the platelets in the depths of the platelet aggregates in the artificial thrombi. Small amounts were seen between some of the degranulated platelets and much more was observed away from the platelet masses. There has been much controversy as to whether or not fibrin formation plays a part in platelet aggregation, and, while the observations with the electron microscope have not resolved this argument, they do indicate that if fibrin is present between the platelets in an aggregate it must be present in very small amounts and in an unfamiliar structural form. Ordinary fibrin strands are easily recognized in the electron microscope by their characteristic periodicity. The simplest hypothesis is that platelet aggregation precedes fibrin formation.

\section{CONCLUSIONS}

The advances in knowledge of the last few years make it possible, tentatively, to describe the morphological sequence of events in the early stages of thrombosis in more detail than has been possible before. It seems that first platelets attach themselves to damaged vessel walls, initially retaining their normal shape. Later the platelet aggregate changes from a loosely packed to a closely packed arrangement. Still later, some of the platelets probably lose their granules by the mechanism described above. Leucocytes then adhere to the degranulated platelets. At or about the same time, fibrin first appears in a recognizable form. It is to be hoped that this clarification of the morphological sequence of events may facilitate a more rational approach than has hitherto been possible to the underlying chemical mechanism of thrombosis.

\section{REFERENCES}

Bizzozero, J. (1882). Virchows Arch. path. Anat., 90, 261. Chandler, A. B. (1958). Lab. Invest., 7, 110.

Cliff, W. J. (1961). D.Phil. Thesis, Oxford University. 
Connor, W. E. (1962). J. clin. Invest., 41, 1199. and Poole, J. C. F. (1961). Quart. J. exp. Physiol., 46, 1.

De Robertis, E., and Vaz Ferreira, A. (1957). Exp. Cell Res., 12, 568. Donné, A. (1842). C. R. Acad. Sci. (Paris), 14, 366.

Eberth, J. C., and Schimmelbusch, C. (1886). Virchows Arch. path. Anat., 103, 39, 105, 331, 456.

Florey, H. W., Greer, S. J., Kiser, J., Poole, J. C. F., Telander, R., and Werthessen, N. T. (1962). Brit. J. exp. Path., 43, 655.

French, J. E. (1962). In General Pathology, 3rd ed., edited by H. W. Florey, p. 234. Lloyd-Luke, London.

- , and Poole, J. C. F. (1963). Proc. roy. Soc. B, 157, 170.

Hand, R. A., and Chandler, A. B. (1962). Amer. J. Path., 40, 469.

Hayem, G. (1877). C.R. Acad. Sci. (Paris), 95, 18.

Hoak, J. C. (1963). In press.

Honour, A. J., and Russell, R. W. Ross (1962). Brit. J. exp. Path., $43,350$.

Iseri, O. A., and Benditt, E. P. (1961). Fed. Proc., 20, 133.

Jones, T. W. (1851). Guy's Hosp. Rep., 7, 1.

- (1852). Phil. Trans., 142, 131.

Kjærheim, Å., and Hovig, T. (1962). Thrombos. Diathes. haemorrh. (Stuttg.), 7, 1.

Levene, M., and Levene, C. I. (1957). J. clin. Path., 10, 200.

Lubnitzky, S. (1885). Arch. exp. Path. Pharm., 19, 185.

Mantegazza, P. (1869). Gazz. med. lombarda, 29, (2), 157. Cited by Welch (1899).
Mustard, J. F., Murphy, E. A., Rowsell, H. C., and Downie, H. (1962). Amer. J. Med., 33, 621.

Palade, G. E. (1959). In Subcellular Particles, edited by T. Hayash p. 64. Ronald, New York.

Parmeggiani, A. (1961). Thrombos. Diathes. haemorrh. (Stuttg.), 517.

Pease, D. C. (1956). Blood, 11, 501.

Policard, A., Collet, A., and Giltaire-Ralyte, L. (1955). Bull. Mic appl., $5,7$.

Poole, J. C. F. (1959). Quart. J. exp. Physiol., 44, 377.

(1960a). Proc. 7th Congr. europ. Soc. Haemat., part 2, p. 646. (1960b). In Pathogenesis and Treatment of Occlusive Arteridi Disease, edited by L. McDonald, p. 40. Pitman, London. (1963). Scientific Basis of Medicine Annual Reviews (in press). and French, J. E. (1961). J. Atheroscler. Res., 1, 251.

Torgersen, O. (1962). T. norske Lageforen., 82, 199.

Welch, W. H. (1887). Reprinted in: William Henry Welch, Papers an Addresses, Baltimore, Johns Hopkins Press, 1920. Vol. I, p. 48

- (1899). In A System of Medicine, edited by T. C. Allbutt, vol. 6. p. 155. Macmillan, London.

Wiener, J., and Spiro, D. (1962). Exp. mol. Path., 1, 554.

Zahn, F. W. (1875). Virchows Arch. path. Anat., 62, 81.

Zimmermann, G. (1845). Arch. Physiol. Heilk., 4, 65. 